\title{
DESIGN AND FABRICATION OF AUTOMATED PNEUMATIC
}

\section{SHEARING MACHINE TO CUT ALUMINIUM SHEET}

\section{PRITISH CHITTE ${ }^{1}$, SACHIN RATHOD ${ }^{2}$, NITIN MOTGI ${ }^{3}$, YOGESH JANGALE ${ }^{4}$ \& RAHUL PATIL ${ }^{5}$ \\ ${ }^{1,2,5}$ Department of Mechanical Engineering, Walchand Institute of Technology, Solapur, Maharashtra, India \\ ${ }^{3,4}$ Department of Mechanical Engineering, Dr. D. Y. Patil Institute of Engineering, Management and}

Research, Pune, Maharashtra, India

\begin{abstract}
Automation within the contemporary world is inevitable. Any automatic machine focuses towards the economical use of man, machine and material well worth the most. For small and tiny scale industrial units the sheet cutting machine is manually operated. In this paper, solenoid valve and Arduino controller is used for automation. The machine works with the help of double acting pneumatic cylinder. The piston is connected to the moving cutter. The machine is easy to transport and transfer. The compressed air from the compressor is used as the force medium for this operation. There are double acting pneumatic cylinders, solenoid valves, flow control valves and the Arduino is used. The arm from the compressor enters to the solenoid valve. The function of solenoid valves all of air correct time interval. The 5/2 solenoid valve is used. At one position the piston is pushed by the air entering the cylinder thus obtaining cutting stroke. The releasing stroke is obtained by the movement of piston in backward direction due to the air entering the cylinder from the other side. The speed of the cutting and releasing stroke is varied by the Arduino controller.

KEYWORDS: Automation, Arduino Controller, Solenoid Valve \& Double Acting Cylinder
\end{abstract}

Received: May 15, 2018; Accepted: Jun 05, 2018; Published: Jul 16, 2018; Paper Id.: IJMPERDAUG201851

\section{INTRODUCTION}

The main objective is achieving some goals like reducing process time, reducing required floor space, improving working environment for the workers, achieving cutting operation without bending, achieving good surface finishing, and doing a full automation to reducing human involvement in cutting operation.

\section{ELEMENTS OF PNEUMATIC SYSTEM}

Pmeumatic System

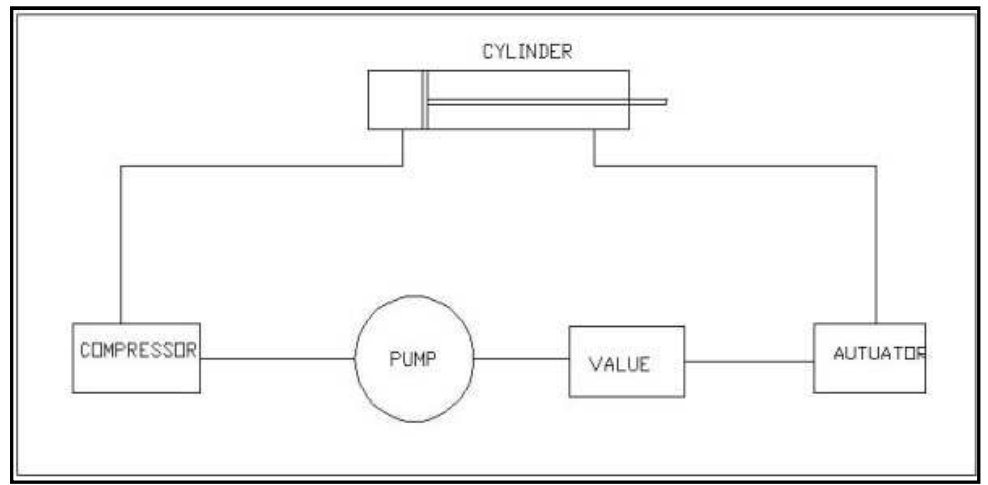

Figure 1: Main Pneumatic System 


\section{Compressor}

The compressor is a device compressing the air and raises its pressure for delivering it to the pneumatic system. The compressor feeds air into a main tank, the main tank's pressure is higher than the pressure required by any single pneumatic animatronic. To reduce the tank pressure as per the requirement of the pneumatic system an adjustable regulator is needed at the tank outlet. On the regulator are two gauges used to read both tank pressure and the output pressure of the regulator.

\section{Solenoid Value}

Solenoid valve is used to adjust the air pressure from the source port to the desired port. The undesired port may act as free exhaust. The valves can be operated electrically or manually.

\section{Pneumatic Cylinder}

The energy stored in compressed air in converted into mechanical motion namely reciprocating linear motion with help of pneumatic cylinders / actuators.

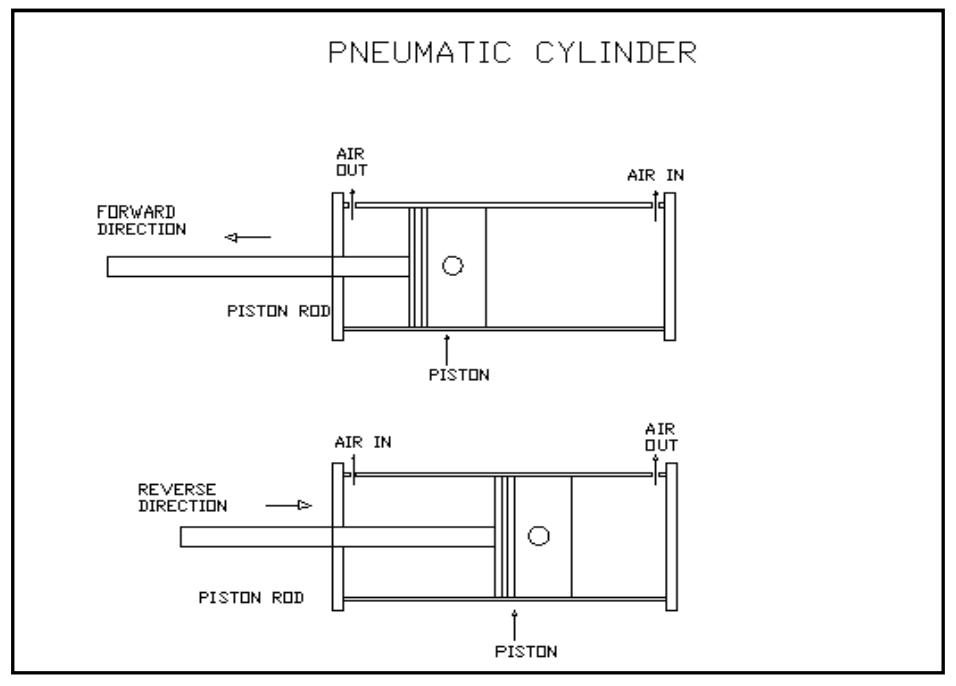

Figure 2: Pneumatic Actuators/Cylinders

Experts prefer the pneumatic devices as they work with low noise, clean operations and small fluid storage space.

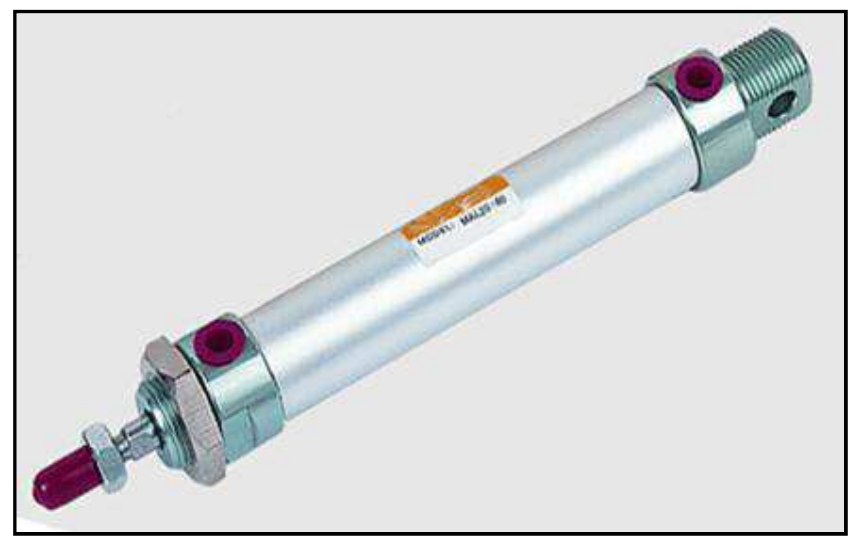

Figure 3: Actual Pneumatic Cylinder/Actuator 


\section{Shearing Blades}

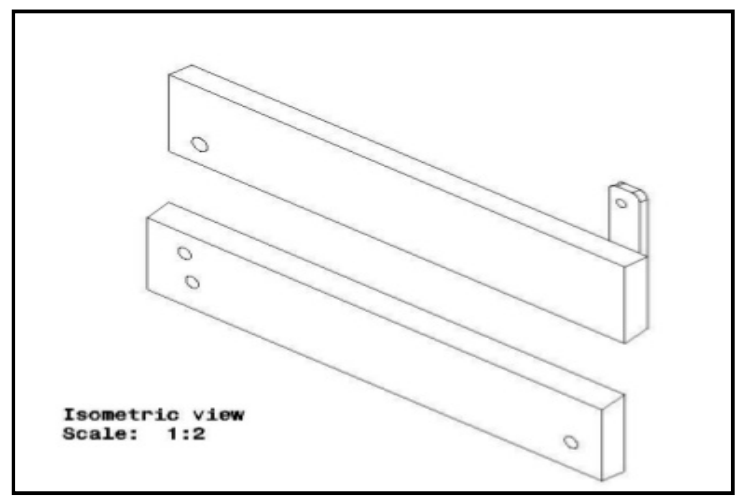

Figure 3: Shearing Blades

The Shearing blade is made up of 35C8 by which the shearing or cutting action of sheet metal is done.

\section{Angle Section}

To give support to shearing blades and avoid vibration during shearing angle section is used

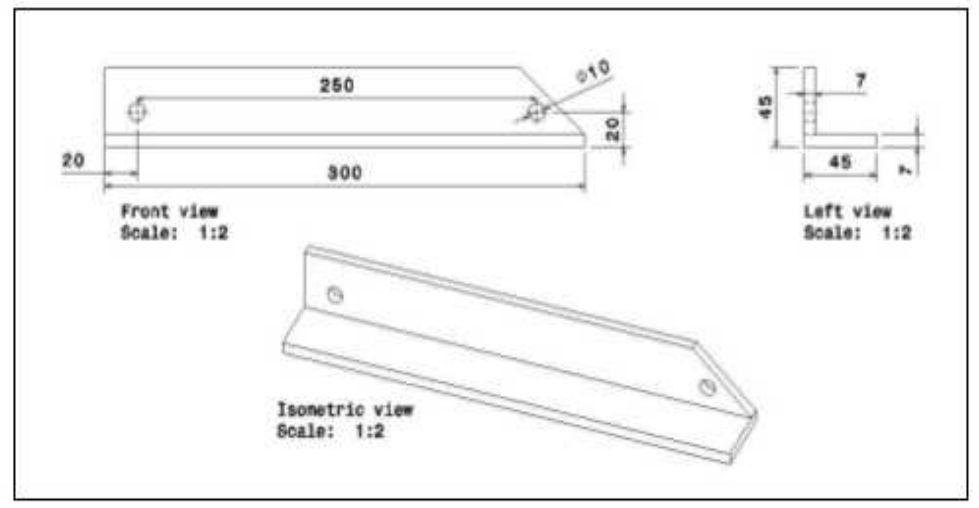

Figure 5: Angle Section

\section{LITERATURE REVIEW}

- Mr. P. Goyal suggested in the paper that machine should be simple to operate and easy to maintain, hence we tried out to develop the Pneumatic Shearing machine. In shearing operation as the punch descends upon the metal, the pressure exerted by the punch first cause the plastic deformation of the metal.

- Mr. Vishal Tambat explained in the paper that the shearing machine is most important in sheet metal industry. This machine should be used for straight cutting machine with wide application. But in some industry hand sheet cutter are used. For that machine to operate the human effort are required.(Ref: "Pneumatic Shearing Machine" ISSN 2393-8471, Vol. 2, Issue 1, pp: (9-18), Month: April 2015 - September 2015)

- Ajit Kumar Singh, Harpreet Singh, Dharmendra Sharma said that in paper that the manually operated machine is converted into pneumatically operated machine by using the solar energy. Hydraulically operated machines are too costlier for small scale and medium scale industries. This paper deals with pneumatically operated cutting machine. The manually operated machine is converted into pneumatically operated machine by applying proper 
design procedure. The design was drawing back using CREO software. At the end of task, the conclusion is made and several recommendations are suggests to make an improvement about the result and the project for future study.

- AbhishekGaonkar, SahilKerkar, NandanShirodkar, VikeshHadfadkar, DeuSangelkar suggest that in paper an insight in to the work we went through to invent the concept for an automated fibre glass sleeve cutting machine. The challenge given to us by the industry was to design and fabricate the shearing machine that can cut fiber glass sleeves in a given desired length automatically on a large scale. the length of the sleeve given to us is in range of $20 \mathrm{~mm}-50 \mathrm{~mm}$.

\section{DESIGN CALCULATION}

- Selection of Cylinder

Length of sheet $(\mathrm{L}) \quad=250 \mathrm{~mm}$

thickness of $\operatorname{sheet}(\mathrm{t}) \quad=2 \mathrm{~mm}$

strength of aluminum sheet $(\operatorname{Tmax})=180 \mathrm{~N} / \mathrm{mm}^{2}$

- CUTTING FORCE $=\mathrm{L} \times \mathrm{t} \times \mathrm{Tmax}$

$$
\begin{aligned}
& =250 \times 2 \times 180 \\
& =90000 \mathrm{~N}
\end{aligned}
$$

- STRIPPING FORCE $=20 \%$ of cutting force

$$
=18000 \mathrm{~N}
$$

- TOTAL FORCE $=\mathrm{C} . \mathrm{F}+\mathrm{S} . \mathrm{F}$

$$
\begin{aligned}
& =90000+18000 \\
& =108000 \mathrm{~N}
\end{aligned}
$$

- AREA OF BLADE $=\mathrm{L} \times \mathrm{W}$

$$
\begin{aligned}
& =300 \times 8 \\
& =2400 \mathrm{~mm}^{2}
\end{aligned}
$$

- PRESSURE = Total force/ Area

$$
\begin{aligned}
& =108000 / 2400 \\
& =45 \mathrm{~N} / \mathrm{mm}^{2} \\
& =4.5 \mathrm{bar}
\end{aligned}
$$

- $\quad$ ASSUME FACTOR OF SAFETY $=1.2$

- PRESSURE $=4.5 \times 1.2=5.4 \mathrm{bar}$ 


\section{CATIA 3D MODELLING AND DRFTING OF AUTOMATED PNEUMATIC SHEARING MACHINE}

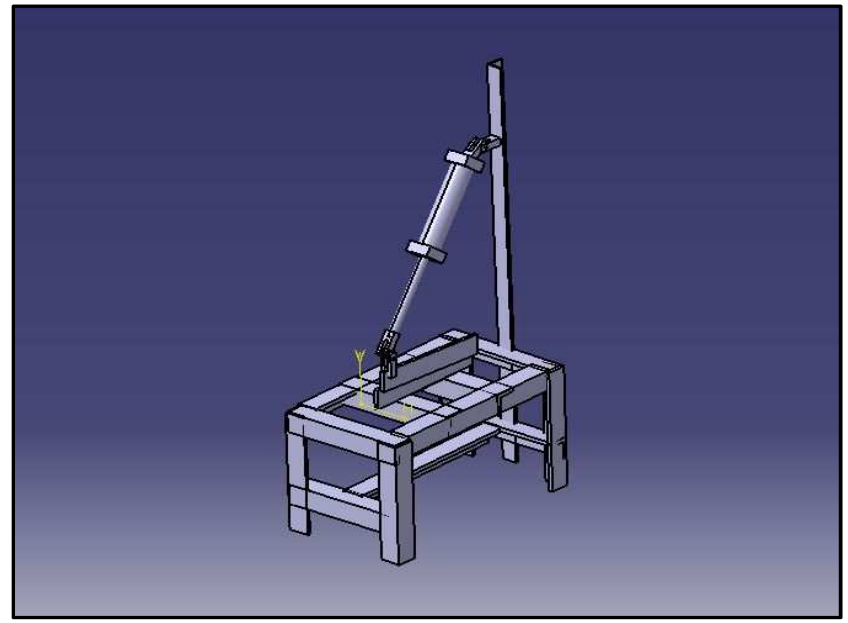

Figure 6: CATIA Modeling of Automated Pneumatic Shearing Machine

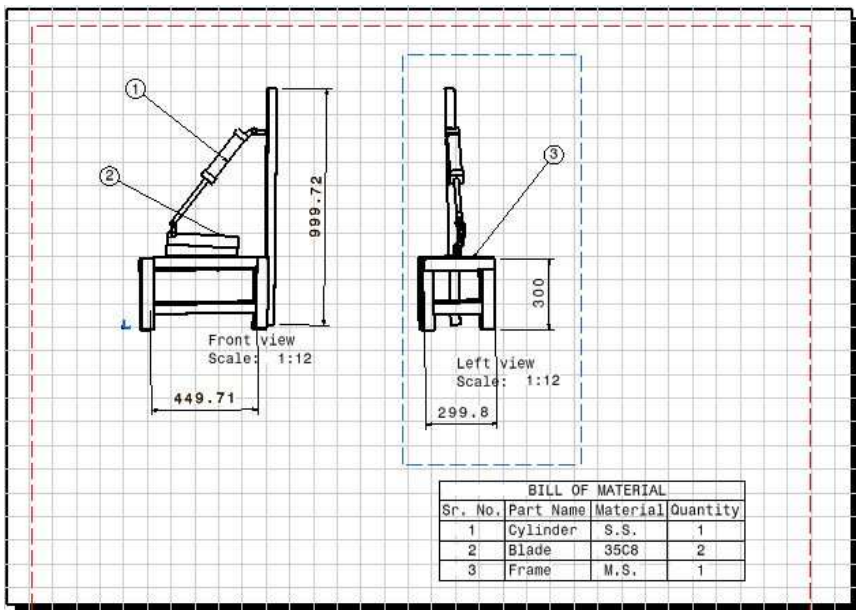

Figure 7: CATIA Drafting of Automated Pneumatic Shearing Machine

Process to be Followed

\section{- Data Search}

Firstly, the data regarding the availability of pneumatic operated shearing machine \& its various materials available in the market with its costing and its manufacturing process was studied as well as case study.

- Design

Designing the pneumatic operated shearing machine, first the cylinder was design for perfect output, with required power. The cutting edges required to the sheet were also the main part of the design.

- Actual Diagram with Parameter

After various designing consideration, the parameters were design in which there was main consideration that the number of parts used should be less in number. 
- Material Selection

It was very necessary that the material used should be light weight, less costly, non-corrosive and can be fixed at a point. So while selecting the material cast iron, aluminum was given first reference.

\section{- Marking}

As there were many processes on the pneumatic operated shearing machine like drilling, cutting, fitting etc. marking was done were ever it was necessary. While Marking on material all parameter which were designed during designing were considered.

\section{- Cutting}

The process of cutting a metal can be stated as a forming process that occurs in the components of the cutting system that are so organized that the external force applied to the cutting system results into the intended fracture of the layer being removed due to the collective stress including the constantly varying bending stress producing a cyclic nature of the process sawing, shaping (or planning), broaching, drilling, grinding, turning and milling are the common cutting processes.

\section{- Drilling}

Producing round holes in a solid material or enlarging existing holes is called as drilling process with the use of multi tooth cutting tools called drills or drill bits. Twist drill is the most commonly used cutting tool among the rest. The bit is pressed against the work piece a rotated at rates from hundreds to thousands of revolutions per minute. This forces the cutting edge against the work piece, cutting off chips from the hole as it is drilled.

\section{- Assembly}

After performing all operations mentioned above the whole parts are assembled together.

\section{- Paint}

After completion of assembly painting is done.

\section{- $\quad$ Testing}

After completing assembly and painting a successful testing of a machine is carried out.

\section{PROCESS SHEET}

Table 1: Process Sheet

\begin{tabular}{|c|l|l|l|c|}
\hline $\begin{array}{c}\text { Sr. } \\
\text { No. }\end{array}$ & Components & $\begin{array}{c}\text { Machining } \\
\text { Processes }\end{array}$ & Tool Use & $\begin{array}{c}\text { Machining } \\
\text { Time } \\
\text { (Min) }\end{array}$ \\
\hline 1 & Bars & Cutting & Cutter & 60 \\
\hline 2 & Bars & Drilling & Drilling M/C & 30 \\
\hline 3 & Table & Welding & - & 150 \\
\hline 4 & Cutter & Welding & - & 30 \\
\hline 5 & Cutter & Drilling & Drilling M/C & 30 \\
\hline 6 & Table & Grinding & Grinder & 60 \\
\hline
\end{tabular}




\section{Actual Automated Pneumatic Shearing Machine}

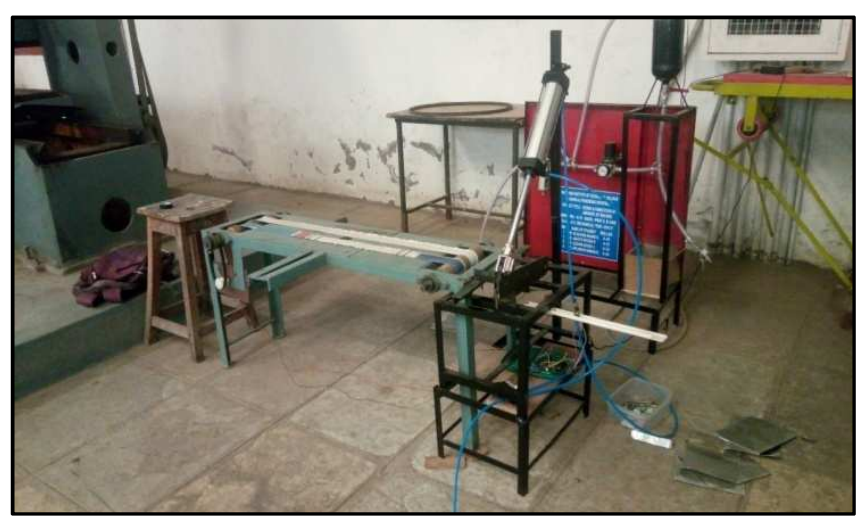

Figure 8: Actual Automated Pneumatic Shearing Machine

\section{CONCLUSIONS}

It can be concluded that Pneumatic shearing machine is more economical as compared to hydraulic one. Higher pressure compressor can be employed for increasing the range of cutting thickness. As far as small sheet metal cutting units are concerned, this device founds to be of greater benefit as it reduces the dependency on the expensive hydraulic shearing machine.

\section{REFERENCES}

1. M. Sorli, L. Gastaldi, E. Codina, S. Heras, Dynamic analysis of pneumatic actuators, Simulation Practice and Theory, 7, 1999, 589-602

2. P. J. Bird, Development in the design and control of pneumatic linear actuators, European Conference on Electrics versus Hydraulics versus Pneumatics, Inst. of Mechanical Engineers, Lond on, In Mechanical Engineering, 1985, 77-83

3. Li Jianfan. Dynamics of pneumatic systems (In Chinese). Guangzhou, SCUT press, 1991.

4. Z. Marciniak, J.L. Duncan, S.J. Hu, Mechanics of Sheet Metal Forming, Second Edition, Butterworth-Heinemann Press, 2002.

5. T. Ohashi, H. Chiba, H. Takano, Employment of Concentrated-Hard Sphere-Suspension Pad for V-bending of Thin Strip, Journal of Achievements in Materials and Manufacturing Engineering 31/2 (2008) 699-704.

6. Gavade, Sourabh., et al. "Automated bluetooth attendance management system." International Journal of Computer Science Engineering and Information Technology Research 5.2 (2015): 7-14.

7. Madhu Kumar V, Arun Kumar N, Harsha B S, Naveen Kumar K N, Nagaraja T.K., Design and Fabrication of Pneumatic Sheet Metal Cuttingand Bending Machine, International Journal of Engineering Research And Advanced Technology (IJERAT), 564-572.

8. SwapnilLaxmanGaikwad, RohitRamnathPawar, MayurBapuGunjal, PritamBajiraoBhawar, Design \& Development Of Pneumatic Shearing Machine, Journal of Advances Research in Science and Engineering,185-192.

9. M.KhajaGulamHussain, T. John babu, Fabrication of Pneumatic Shearing Machine, International Journal for Research Trends and Innovation, 23-32.

10. Saha, Satyajit, Tapan Kumar Das, and Rahul Bhattacharya. "Fabrication of ZnSe based Dye Sensitised Solar Cell and its Characterization." 
11. V. B. Bhandari, Design of Machine Element, McGraw Hill Education (India) Pvt. Ltd., $3^{\text {rd }}$ Edition, 1994.

12. Basics of Pneumatics and Pneumatic Systems Retrieved from - http://ispatguru.com/basics-of-pneumatics-and-pneumaticsystems/.

13. The Absolute Beginner's Guide to Arduino Retrieved from - http://forefront.io/a/beginners-guide-to-arduino/

14. Basic Rules For Beginners In Automation Testing Retrieved from - https://blog.testfort.com/automated-testing/10-basic-rulesfor-beginners-in-automation-testing 